Int. J. Electrochem. Sci., 13 (2018) $6626-6642$

\title{
Influence of Annealing Temperature on Photocatalytic and Electrochemical Sensing Properties of $\mathrm{SnO}_{2} / \mathrm{ZnO}$ Nanocomposites
}

\author{
Atif Mossad Ali, ${ }^{1,2}$, Omniat Qreshah ${ }^{3}$, Adel A. Ismail ${ }^{4}$, Farid A. Harraz ${ }^{4,5}$, Hamed Algarni ${ }^{1}$, Mohd \\ Faisal $^{5}$, Wee Siong Chiu 6 \\ ${ }^{1}$ Department of Physics, Faculty of Science, King Khalid University, Abha, Saudi Arabia \\ ${ }^{2}$ Department of Physics, Faculty of Science, Assiut University, Assiut, Egypt \\ ${ }^{3}$ Physics Department, Faculty of Arts \& Science, Najran University, Saudi Arabia \\ ${ }^{4}$ Nanostructured Materials and Nanotechnology Division, Central Metallurgical Research and \\ Development Institute, Cairo, Egypt \\ ${ }^{5}$ Promising Centre for Sensors and Electronic Devices (PCSED), Advanced Materials and Nano- \\ Research Centre, Najran University, Najran, Saudi Arabia \\ ${ }^{6}$ Low Dimensional Materials Research Centre, Department of Physics, Faculty of Science, University \\ of Malaya, Kuala Lumpur, Malaysia \\ *E-mail: atifali@kku.edu.sa
}

doi: $10.20964 / 2018.07 .200$

Received: 20 February 2018 / Accepted: 24 March 2018 / Published: 5 June 2018

$\mathrm{SnO}_{2} / \mathrm{ZnO}$ nanocomposites were prepared by sol-gel technique in the presence of polyethylene glycol, followed by annealing at various temperatures ranging from 600 to $1000{ }^{\circ} \mathrm{C}$. The prepared $\mathrm{SnO}_{2} / \mathrm{ZnO}$ were studied by XRD, FTIR, FT-Raman,TEM, UV-vis DR spectroscopy, photoluminescence spectroscopy, and nitrogen adsorption-desorption isotherm analysis. The crystal phases and energy gap of the $\mathrm{SnO}_{2} / \mathrm{ZnO}$ nanocomposites were modified with annealing temperatures. The photocatalytic activity of the prepared $\mathrm{SnO}_{2} / \mathrm{ZnO}$ nanocomposites for the decomposition of methylene blue (MB) dye was examined under visible light illumination. It was found that photodegradation rate of the prepared photocatalysts for the decomposition of $\mathrm{MB}$ decreased linearly upon increasing the annealing temperature from 600 to $1000{ }^{\circ} \mathrm{C}$. The maximum photocatalytic efficiency (100\%) was obtained for the $\mathrm{SnO}_{2} / \mathrm{ZnO}$ nanocomposite annealed at $600{ }^{\circ} \mathrm{C}$. The photocatalytic activity of the $\mathrm{SnO}_{2} / \mathrm{ZnO}$ nanocomposite was dependent on their surface areas and bandgap values. The optimal $\mathrm{SnO}_{2} / \mathrm{ZnO}$ nanocomposite annealed at $600{ }^{\circ} \mathrm{C}$ was also used for the electrochemical sensing of liquid ethanol showing significant sensing response with a high sensitivity of $20.09 \mu \mathrm{AmM}^{-1} \mathrm{~cm}^{-2}$ and a limit of detection of $25.2 \mu \mathrm{M}$ ethanol concentration.

Keywords: $\mathrm{SnO}_{2} / \mathrm{ZnO}$; Nanocomposites; Sol-gel; Photocatalyst; Photodegradation 


\section{FULL TEXT}

(C) 2018 The Authors. Published by ESG (www.electrochemsci.org). This article is an open access article distributed under the terms and conditions of the Creative Commons Attribution license (http://creativecommons.org/licenses/by/4.0/). 